\title{
PADRONIZAÇÃO DE METODOLOGIA PARA DETERMINAÇÃO DE ÁCIDO PROPIÔNICO EM PÃES DE FORMA ${ }^{1}$
}

\author{
CAMPOS, Gisélia ${ }^{2}$; NELSON, David L. ${ }^{3}$; RIBEIRO-CUNHA, Mariem R. ${ }^{2}$; FRANKLIN, Heloisa M. O. H. ${ }^{2}$; \\ GOMIDES, Maria F. ${ }^{2}$; NAVEIRA, Rita M. P. ${ }^{2}$ \& PEIXOTO, Tânia M. A. G. ${ }^{2}$
}

\section{RESUMO}

Alguns tipos de pães para sanduíches são sensiveis à contaminação por bolores e leveduras. Por isso a legislação brasileira de alimentos permite a adição de propionato de cálcio no limite máximo de $0,2 \%$. A cromatografia gasosa é um método utilizado para quantificação do ácido propiônico, sendo necessária a etapa de extração desse ácido do pão que comumente se encontra sob a forma de propionato de cálcio. Foram feitos vários testes utilizandose métodos de extração por arraste à vapor, extração etérea contendo $3 \%$ de ácido ortofosfórico e extração direta com solução aquosa de ácido fórmico $0,05 \mathrm{M}$. Foram também testadas várias colunas cromatográficas e verificado o comportamento do ácido isovalérico, ácido butírico e metil isobutil cetona (MIBK) como padrōes internos. Em função dos melhores resultados obtidos, optouse por extrair 0 ácido propiônico com solução etérea de ácido fórmico $3 \%$, usando ácido butírico como padrão interno e análise cromatográfica na coluna DEGS. A recuperação média de $97,4 \%$ foi obtida com propionato de cálcio padrão e de $85,0 \%$ com amostras de pão adicionadas de propionato de cálcio. O método mostrou-se preciso, rápido e de fácil execução.

Palavras-chave: conservador; propionato de cálcio; pão

\section{SUMMARY}

PADRONIZATION OF THE METHODOLOGY FOR DETERMINATION OF PROPIONIC ACID IN BREAD LOAVES. Some kinds of bread for sandwiches are susceptible to contamination by mold and yeast. Therefore, the brazilian food law allows the use of propionate salts to prevent growth of these microorganisms. The maximum level allowed is $0.2 \%$. Gas chromatographic analysis is the method used to quantify propionic acid, which must be extracted from bread that contains these salts, usually calcium propionate. Several tests were performed, using different extraction methods such as steam distillation or extraction with ether containing $0.3 \%$ phosphoric acid or $0.05 \mathrm{M}$ formic acid. Three different chromatographic columns and three different internal standards - isovaleric acid, butyric acid and isobutyl methyl ketone (MIBK) were tested. The use of a DEGS column, with butyric acid as internal standard and extraction of propionic acid with $3 \%$ formic acid in ether was chosen. The recovery of calcium propionate from a standard solution by this method was $97.4 \%$, while that obtained with samples of bread spiked with this salt was $85 \%$. This method was found to be rapid, precise and easy to execute.

Key words: conservative, calcium propionate, bread.

\section{1 - INTRODUÇÃO}

Alguns tipos de pães como pão de forma, pão para cachorro quente, hamburguer e outros são sensiveis à

\footnotetext{
1 Recebido para publicação em 18/10/95. Aceito para publicação em 31/7/97.

2 Fundação Ezequiel Dias, Divisão de Bromatologia e Toxicologia, Setor de Química Bromatológica, 30.510-010 Belo Horizonte, MG. 3 Universidade Federal de Minas Gerais, Depto. de Alimentos, Faculdade de Farmácia, 30180-112 Belo Horizonte, MG.
}

contaminação por bolores e leveduras. Por isso, é necessária a adição de agentes como propionato de cálcio ou sódio que ajudam na conservação desses produtos, principalmente quando eles são expostos a venda em locais como supermercados e trailers, onde o consumo não é imediato. A toxicidade do ácido propiônico para fungos e bactérias está relacionada com a incapacidade desses microrganismos para metabolizá-lo. Em mamíferos é metabolizado de maneira similar a outros ácidos graxos, não apresentando efeitos tóxicos no nível permitido pela legislação de alimentos que, no Brasil, é $0,2 \%(\mathrm{p} / \mathrm{p})$ em ácido propiônico $(2,5)$. Portanto, é necessária a padronização de um método rápido e preciso para ser aplicado na rotina de um laboratório de análise de alimentos como parte de um programa de apoio às açōes de Vigilância Sanitária.

Em geral, a quantificação do ácido propiônico é feita por cromatografia gasosa, sendo necessária a transformação dos sais de cálcio, sódio ou potássio em ácido propiônico para extração e análise posterior. De acordo com Jones (3), a liberação do ácido propiônico pode ser feita por arraste de vapor em presença de $\mathrm{H}_{2} \mathrm{SO}_{4}(1 \mathrm{~N})$, ácido fosfotungstico $(20 \%)$ e $\mathrm{MgSO}_{4} \cdot 7 \mathrm{H}_{2} \mathrm{O}$ e a cromatografia gás-sólido em coluna de vidro empacotada com Porapak- $Q$ e ácido butiríco como padrão interno. Abrantes (1) utilizou a extração com solução etérea contendo $3 \%$ de ácido ortofosfórico e ácido isovalérico como padrão interno. A quantificação foi feita por cromatógrafo à gás com detector de ionização de chama, usando coluna de vidro empacotada com $10 \%$ DEGS sobre Chromosorb W tratada com $1 \%$ de ácido ortofosfórico. Lamkin (4) baseia-se na extração do propionato de cálcio das amostras de pão com solução de ácido fórmico $0,05 \mathrm{M}$, filtração em filtro Millex $S Q$ e utilização de ácido n-butírico como padrão interno. A análise cromatográfica foi feita em coluna de vidro borosilicato Carbopack $\mathrm{C}$ de $75 \mathrm{~cm} \times 4 \mathrm{~mm}$, coberta com 0,3\% Carbowax $20 \mathrm{M}$ e 0,1\% ácido ortofosfórico.

\section{2- MATERIAL E MÉTODOS}

\section{1 - Material}

Pão de forma, padrões de propionato de cálcio e de sódio (Sigma, 99\%), ácido propiônico (Riedel, 99,5\%), ácido isovalérico (Sigma, 99,0\%), ácido butírico (Merck-Schuchardt, 99\%) e metil isobutil cetona (MIBK, Pro Analysi, $99 \%)$.

\section{2 - Equipamento}

Cromatógrafo a gás CG Advanced 500A com detector de ionização de chama acoplado ao integrador CG 300. 


\section{3 - Amostragem}

Foram coletadas pela Administração Regional Oeste da prefeitura de Belo Horizonte doze amostras de pão de forma em diferentes estabelecimentos comerciais.

\section{4 - Métodos}

\subsection{1 - Padronização das condições cromatográficas em fase gás-líquida com utilização de padrões em três diferentes colunas}

Coluna Carbowax 20M, 0,53 mm x $30 \mathrm{~m}$, Megabore. Foi utilizado $\mathrm{N}_{2}$ como gás de arraste com fluxo de $8 \mathrm{~mL} / \mathrm{min}$. Foi adaptado o sistema de "make up" para melhor resposta do detector, com fluxo de $22 \mathrm{~mL} / \mathrm{min}$. Para o $\mathrm{H}_{2}$, o fluxo foi $30 \mathrm{~mL} / \mathrm{min}$ e para o ar, $300 \mathrm{~mL} / \mathrm{min}$. A temperatura do injetor foi $200^{\circ} \mathrm{C}$ e do detector, $250^{\circ} \mathrm{C}$. A coluna foi aquecida a $50^{\circ} \mathrm{C}$ por $3 \mathrm{~min}$, com aumento de $8^{\circ} \mathrm{C} / \mathrm{min}$ até atingir $160^{\circ} \mathrm{C}$. Foi utilizado ácido isovalérico como padrão interno. Optou-se por trabalhar com soluções padrão na concentração de 0,5 $\mathrm{mg} / \mathrm{mL}$ e volume injetado de $1 \mu \mathrm{L}$.

Coluna Porapak Q, 1/8" x 1,8 m em aço inoxidável. Foram utilizadas as temperaturas de $220^{\circ} \mathrm{C}$ e $250^{\circ} \mathrm{C}$ para o injetor e o detector, respectivamente, utilizando duas combinações de fluxo dos gases. Fluxo 1: $\mathrm{N}_{2}$ e $\mathrm{H}_{2}=40 \mathrm{~mL} / \mathrm{min}$ e $\mathrm{Ar}=400 \mathrm{~mL} / \mathrm{min}$. Fluxo 2: $\mathrm{N}_{2}$ e $\mathrm{H}_{2}=30 \mathrm{~mL} / \mathrm{min}$ e $\mathrm{Ar}$ $=300 \mathrm{~mL} / \mathrm{min}$. Para a coluna, foram utilizadas várias temperaturas isotérmicas e algumas com programação. Isotérmicas: $204^{\circ} \mathrm{C} ; 205^{\circ} \mathrm{C} ; 210^{\circ} \mathrm{C} ; 215^{\circ} \mathrm{C}$. Com programação: 1) $\mathrm{T}_{\mathrm{i}}$ $=195^{\circ} \mathrm{C}$ por $2 \mathrm{~min}$., rampa $=3^{\circ} \mathrm{C} / \mathrm{min}, \mathrm{T}_{f}=205^{\circ} \mathrm{C}$. 2) $\mathrm{T}_{i}=$ $195^{\circ} \mathrm{C}$ por $3,5 \mathrm{~min}$. rampa $=2^{\circ} \mathrm{C} / \mathrm{min}, \mathrm{T}_{\mathrm{f}}=205^{\circ} \mathrm{C}$.

Nestas condições, foram injetadas de 0,5 a 2,0 $\mu \mathrm{L}$ de várias soluções para escolha do padrão interno e da melhor condição de análise: ácido fórmico $0,05 \mathrm{M}$ e 3\% em éter etílico; ácido propiônico $5 \%$ e 3\% em ácido fórmico 0,05 M em éter etílico; ácido isovalérico $2,5 \%$ em ácido fórmico 0,05 $\mathrm{M}$ em éter etílico; metil isobutil cetona $0,1 \%$ em ácido fórmico $0,05 \mathrm{M}$ em éter etílico.

Coluna DEGS $10 \%$ mais Ácido Ortofosfórico sobre Chromossorb W, 1,8 polegados $\times 6$ pés em áço inoxidável. Foi utilizado o fluxo de $30 \mathrm{~mL} / \mathrm{min}$ para o gás de arraste $\left(\mathrm{N}_{2}\right)$ e para $\circ \mathrm{H}_{2}$. O fluxo do ar foi $300 \mathrm{~mL} / \mathrm{min}$. As temperaturas do injetor $\theta$ detector foram $220^{\circ} \mathrm{C}$ e $250^{\circ} \mathrm{C}$, respectivamente. A programação da coluna foi: $T_{i}=90^{\circ} \mathrm{C}$ por $3 \mathrm{~min}$, rampa $=1^{\circ} \mathrm{C} / \mathrm{min}, \mathrm{T}_{\mathrm{f}}=115^{\circ} \mathrm{C}$. Injetou-se $1 \mu \mathrm{L}$ de solução padrão de ácido propiônico $0,1 \%$ e ácido butírico $0,2 \%$ em éter.

\subsection{2 - Padronização do método utilizado para extração e quantificação do ácido propiônico}

Como estudo preliminar, foram testados três métodos de análise, sendo introduzidas algumas modificações para adaptá-los às condições laboratoriais, utilizando-se a coluna Carbowax 20M. No método de JONES (3), foi utilizada extração em amostras de pão e padrões de propionato de cálcio por arraste à vapor, acidificando-se com ácido ortofosfórico, ácido clorídrico e ácido fórmico, reextraindo-se o destilado com éter e álcool. No método de ABRANTES (1), foi realizada extração conforme a técnica descrita. O método de LAMKIM (4) foi realizado retomando-se o extrato com éter.

O método padronizado neste trabalho consistiu em extrair o ácido propiônico de $1,0 \mathrm{~g}$ de pão de forma em um tubo de vidro contendo $4 \mathrm{~mL}$ de solução de ácido fórmico $3 \%$ em éter e $1 \mathrm{~mL}$ de ácido butírico $1 \%$ em éter como padrão interno, agitando-se com um bastão de vidro por 5 min em banho de gelo. Após decantação, foi injetado $1 \mu \mathrm{L}$ desta solução no cromatógrafo, segundo condições padronizadas para a coluna DEGS. Os cálculos foram feitos através do fator de correção obtido pelo integrador.

Para escolha do padrão interno, 35 amostras de pão de forma foram analisadas pelo procedimento acima, utilizando ácido butírico como padrão interno. Estas mesmas amostras foram re-analisadas substituindo o ácido butírico por ácido isovalérico. MIBK também foi testado como padrão interno, não sendo detectado na coluna DEGS.

\subsection{3 - Estudo da recuperação e precisão do método utilizado}

Duas amostras de aproximadamente $10 \mathrm{~g}$ de pão de forma fabricado sem utilização de conservador foram adicionadas de propionato de cálcio, nas concentrações de cerca de 0,1 e $0,2 \%$, respectivamente. Foram feitas extrações conforme descrito na padronização anterior, utilizando aproximadamente $1 \mathrm{~g}$ das amostras preparadas. Paralelamente, foi feito o branco e análises de padrões de propionato de cálcio, com teor de pureza de $99 \%$.

Com o objetivo de se verificar a precisão e exatidão da resposta do cromatógrafo, foi injetada uma solução padrão contendo ácido propiônico na concentração de 99,5ppm, usando ácido butírico como padrão interno, e outra da mesma concentração, tendo ácido isovalérico como padrão interno. Após o procedimento para obtenção do fator de resposta, essa mesma solução e outras duas da mesma concentração foram injetadas em triplicata como se fossem amostras e os teores de ácido propiônico foram calculados. O mesmo procedimento foi aplicado com ácido isovalérico, utilizando-se duas soluções em triplicata. Foi aplicado o teste de $\mathrm{F}$ para a análise dos resultados. Para estudo da precisão do método foram analisadas, em triplicata, 12 amostras de pão de forma coletadas no comércio da região oeste de Belo Horizonte.

\section{3-RESULTADOS E DISCUSSÃO}

De acordo com os testes realizados, o método de ABRANTES não mostrou resultados satisfatórios. $O$ de JONES, utilizando-se ácido fórmico e éter e o de LAMKIM mostraram bons resultados. Optou-se então pelo método de LAMKIM modificando-se o solvente para éter e aumentando a concentração de ácido fórmico para $3 \%$ a fim de melhorar a extração.

Tanto a coluna Carbowax $20 \mathrm{M}$ quanto a DEGS mostraram-se eficientes quando se trabalhou com éter. A dificuldade observada resume-se no próprio manuseio do éter que é muito volátil e exige um tratamento prévio com alumina para eliminar peróxidos. A coluna Porapak $Q$, na qual pode ser injetada solução aquosa diretamente, seria a mais indicada. Entretanto, mesmo alterando as condições de análises, os cromatogramas apresentaram picos de base alar- 
gada e baixa resolução. Como obteve-se boa resolução tanto com a Carbowax quanto com a DEGS, optamos por trabalhar com esta última. Quanto às substâncias escolhidas para padrão interno, o ácido isovalérico foi indicado tanto para a coluna Carbowax $20 \mathrm{M}$ quanto para a DEGS. $O$ ácido butírico foi indicado para a DEGS e o MIBK para a Porapak Q (Tabela 1). As condições cromatográficas estão descritas no item 2.4.1, sendo que para a coluna Porapak $Q$, a temperatura utilizada foi $204^{\circ} \mathrm{C}$.

TABELA 1. Análise cromatográfica de soluções contendo ácido propiônico padrão e diferentes substâncias como padrão interno.

\begin{tabular}{lccccc}
\hline \multirow{2}{*}{ Coluna } & \multicolumn{5}{c}{ Tempo de retenção } \\
\cline { 2 - 6 } & Solvente & $\begin{array}{c}\text { Ác. } \\
\text { propiônico }\end{array}$ & $\begin{array}{c}\text { Ác. } \\
\text { isovalérico }\end{array}$ & MIBK & $\begin{array}{c}\text { Ác. } \\
\text { butírico }\end{array}$ \\
\hline Carbowax 20M & éter & 5,0 & 7,0 & NT & NT \\
DEGS & éter & 4,2 & 7,3 & ND & 6,2 \\
Porapak Q & água & 4,5 & 4,6 & 9,7 & 8,5 \\
\hline
\end{tabular}

$\mathrm{NT}$ - não testado; $\mathrm{ND}$ = não detectado

A Tabela 2 mostra o resultado de doze amostras de pão de forma analisadas em triplicata. $O$ desvio padrão relativo variou de 0,3 a $8,6 \%$ com um resultado médio de $2,6 \%$, mostrando uma boa precisão.

TABELA 2. Teor de propionato de cálcio em amostras de pão de forma comercializadas na região oeste de Belō Horizonte.

\begin{tabular}{ccc}
\hline$N^{2}$ da amostra & $\begin{array}{c}\text { Ácido propiônico* } \\
\%(\mathrm{p} / \mathrm{p})\end{array}$ & $\begin{array}{c}\text { Desvio-padrão } \\
\text { relativo }(\%)\end{array}$ \\
\hline 01 & $0,308 \pm 0,005$ & 1,6 \\
02 & $0,202 \pm 0,002$ & 1,0 \\
03 & $0,058 \pm 0,005$ & 8,6 \\
04 & $0,290 \pm 0,005$ & 1,7 \\
05 & $0,184 \pm 0,005$ & 2,7 \\
06 & $0,051 \pm 0,001$ & 2,0 \\
07 & $0,171 \pm 0,008$ & 4,7 \\
08 & $0,186 \pm 0,006$ & 3,2 \\
09 & $0,258 \pm 0,005$ & 1,9 \\
10 & $0,114 \pm 0,001$ & 0,9 \\
11 & $0,269 \pm 0,006$ & 2,2 \\
12 & $0,352 \pm 0,001$ & 0,3 \\
\hline
\end{tabular}

* ánalises realizadas em triplicatas

A Tabela 3 mostra os resultados da análise com ácido isovalérico e ácido butírico como padrão interno. Para tanto, injetou-se várias vezes uma solução de ácido propiônico contendo ácido butírico e outras vezes contendo ácido isovalérico. $\mathrm{O}$ teste de $\mathrm{F}$ mostrou que houve diferença signifi- cativa, ao nível de 5\%, entre os dois padrões, sendo o ácido butírico considerado o melhor. Este teste foi realizado com injeção direta no cromatógrafo sem a etapa de extração para reduzir a possibilidade de erro, acentuando pequenas diferenças entre eles. No entanto, este mesmo estudo feito com 35 amostras de pão de forma e com os resultados submetidos à estratégia de análise de pareamento, mostrou que não houve diferença significativa entre os dois padrões, devido à etapa de extração, num intervalo de confiança de $95 \%$.

TABELA 3. Estudo da precisão da resposta cromatográfica com utilização de soluções padrões contendo ácidos butírico $\theta$ isovalérico como padrão interno $\theta$ acido propiônico na concentração de $0,095 \mu \mathrm{L} / 100 \mu \mathrm{L}$.

\begin{tabular}{ccc}
\hline \multirow{2}{*}{ Análise } & \multicolumn{2}{c}{ Concentração encontrada } \\
\cline { 2 - 3 } & Ácido butírico & Ácido isovalérico \\
\hline 1 & 0,101 & 0,109 \\
3 & 0,103 & 0,108 \\
4 & 0,102 & 0,106 \\
5 & 0,103 & 0,109 \\
6 & 0,104 & 0,109 \\
7 & 0,102 & 0,107 \\
8 & 0,103 & - \\
9 & 0,104 & - \\
X & 0,102 & - \\
S & 0,1026 & 0,1080 \\
CV & 0,0010 & 0,0013 \\
\hline
\end{tabular}

O ácido butírico foi preferido porque apresenta odor menos desagradável e menos persistente no ambiente do que o isovalérico. Porém, por ser o ácido butírico um componente natural da manteiga, podendo estar presente no material analisado, sua utilização implica em uma análise prévia da amostra, devendo ser substituido caso esteja presente como ingrediente do produto.

A Tabela 4 mostra a exatidão do método expressa em porcentagem de recuperação do ácido propiônico proveniente de propionato de cálcio adicionado a uma amostra de pão de forma isento deste produto, em quantidades correspondentes ao valor máximo permitido $(0,200 \%)$ e a metade deste valor. Mostra também a porcentagem de recuperação do ácido propiônico proveniente de padrão de propionato de cálcio puro.

As Figuras 1 a 6 mostram alguns cromatogramas das análises realizadas. Como pode ser visto nas Figuras 1 a 3, os melhores resultados foram obtidos com a coluna DEGS e, nessa coluna, o ácido butírico tem um tempo de retenção mais proximo ao do ácido propiônico e seu pico tem um caldo menor do que o do ácido isovalerico, o que permite uma integração mais precisa. 
TABELA 4. Estudo da recuperação do ácido propiônico à partir de padrão de proprionato de cálcio e de amostras de pão de forma adicionadas de propionato.

\begin{tabular}{lccc}
\hline \multirow{2}{*}{ Material analisado } & \multicolumn{3}{c}{ Concentração de ácido propriônico } \\
\cline { 2 - 4 } & $\begin{array}{c}\text { valor } \\
\text { encontrado }\end{array}$ & valor teórico & recuperação \\
\hline Pão de forma & 0,081 & 0,0998 & 80,70 \\
Pão de forma & 0,090 & 0,100 & 89,80 \\
Pão de forma & 0,170 & 0,200 & 85,00 \\
Pão de forma & 0,168 & 0,200 & 84,40 \\
Pão de forma & 0,170 & 0,200 & 85,10 \\
\hline \% recuperação média & & & $85,00 \pm 3,2$ \\
\hline Propionato de cálcio & 83,80 & 79,57 & 105,32 \\
Propionato de cálcio & 84,52 & 79,57 & 106,23 \\
\hline Propionato de cálcio & 82,07 & 79,57 & 103,14 \\
Propionato de cálcio & 70,12 & 79,57 & 88,13 \\
\hline Propionato de cálcio & 74,92 & 79,57 & 84,16 \\
\hline \% recuperação média & & & $97,4 \pm 10,4$ \\
\hline
\end{tabular}

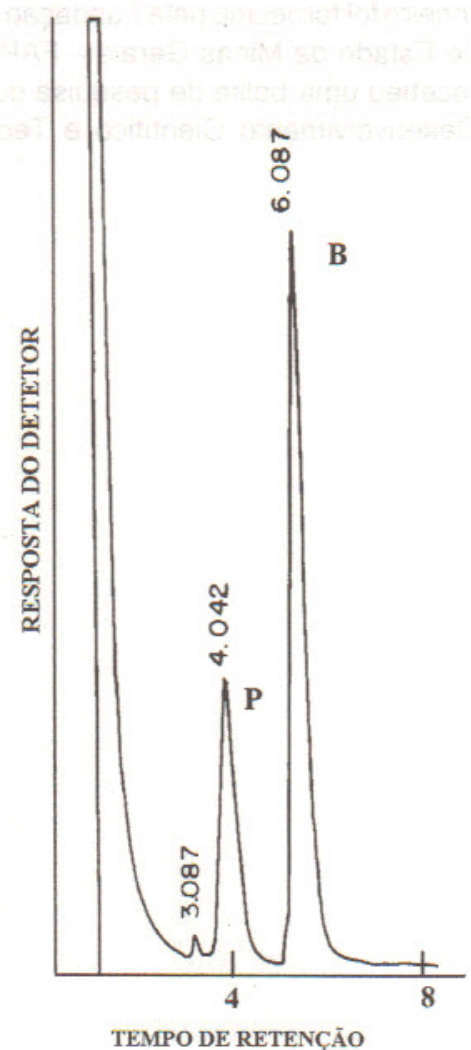

FIGURA 1. Cromatograma da solução padrão de ácido propiônico $(\mathrm{P})$ e ácido butírico $(\mathrm{B})$, Coluna DEGS.

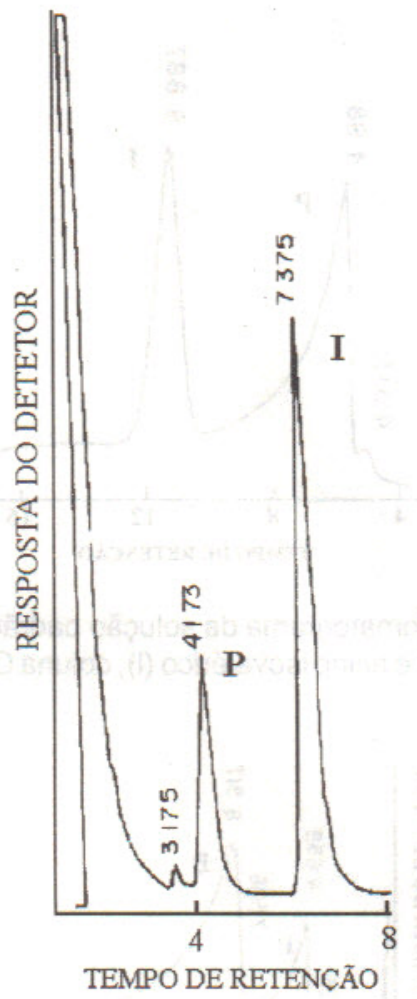

FIGURA 2. Cromatograma da solução padrão de ácido propiônico $(P)$ e ácido isovalérico (I), Coluna DEGS.

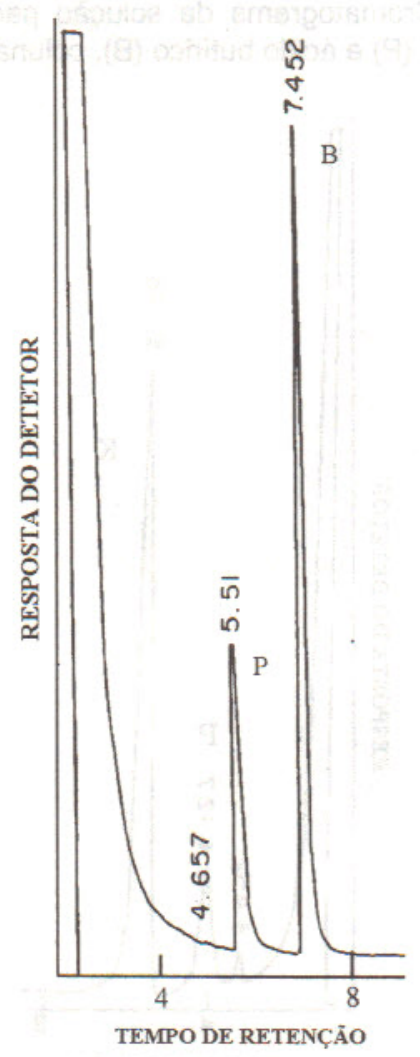

FIGURA 3. Cromatograma da extração de uma amostra de pão forma utilizando ácido butírico (B) como padrão interno, coluna DEGS ( $\mathrm{P}=$ ácido propiônico). 


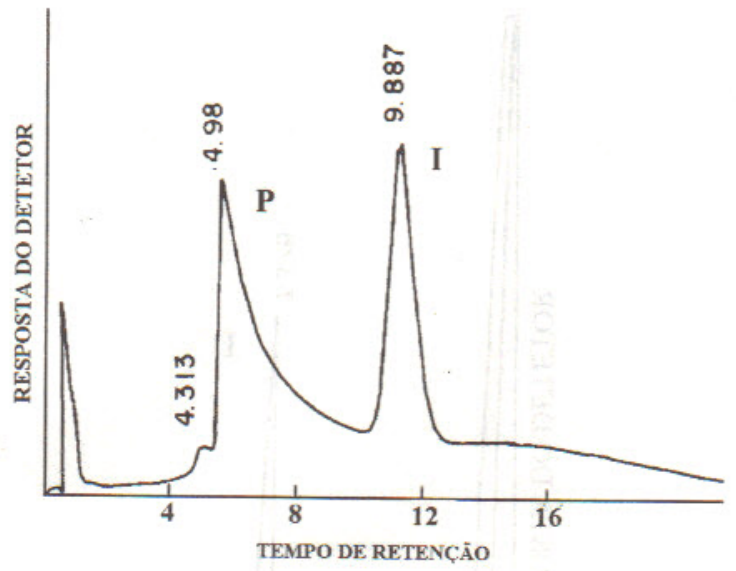

FIGURA 4. Cromatograma da solução padrão de ácido propiônico $(\mathrm{P})$ e ácido isovalérico $(\mathrm{I})$, coluna Carbowax $20 \mathrm{M}$.

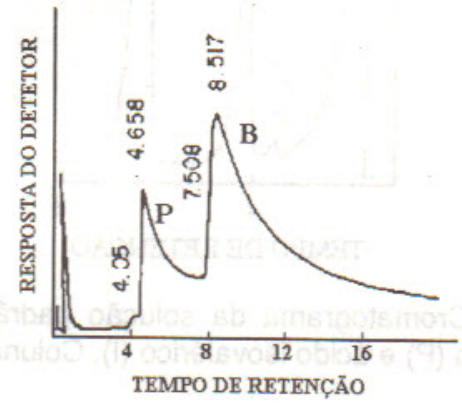

FIGURA 5. Cromatograma da solução padrão de ácido propiônico (P) e ácido butírico (B), coluna Porapak-Q.

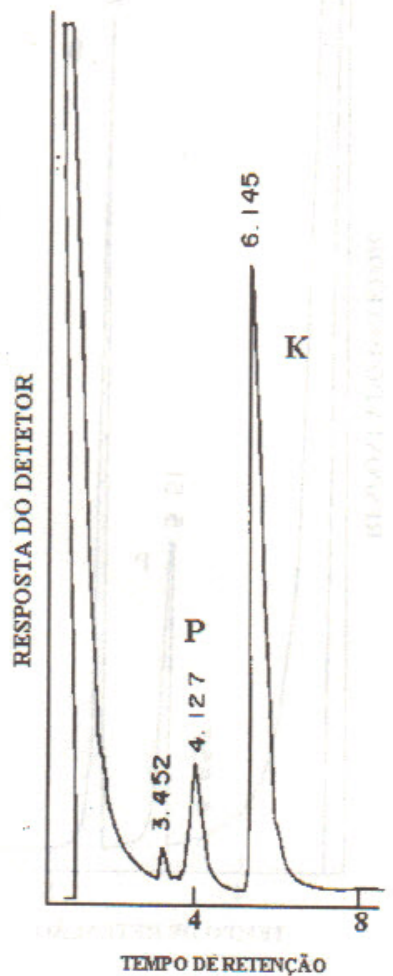

FIGURA 6. Cromatograma da solução padrão de ácido propiônico (P) e MIBK (K), coluna Porapak-Q

\section{4-CONCLUSÕES}

A extração do ácido propiônico com éter adicionado de ácido fórmico mostrou-se eficiente e precisa por ter apresentado boa recuperação (acima de $85 \%$ ) e resultados repetitivos na análise das amostras em triplicata. É um método rápido, podendo ser aplicado com segurança na determinação de ácido propiônico em pães de forma.

\section{5-REFERÊNCIAS BIBLIOGRÁFICAS}

(1) ABRANTES, S. M.; MORAES, O. G. Determinação de Acido Propiônico em Pão por Cromatografia Gás-Liquido. In: Encontro Nacional de Analistas de Alimentos, 3, Florianópolis, 4-8 Outubro, 1987.

(2) BRASIL, Leis, Decretos, Etc. Resolução no. 04/Diário Oficial, Brasília, p. 24716-23, 24 de novembro. M.S. Conselho Nacional de Saúde, 1988.

(3) JONES, B. F. Gas-solid Chromatographic Determination of Propionates in Bakery Products. J. Assoc. Off. Anal. Chem. 56(60): 1415-8, 1973.

(4) LAMKIN, W. M., UNRUH. N. C. \& POMERANZ, Y. Gas Chromatographic Determination of Calcium Propionate Added as Preservative to Bread. J. Assoc. Off. Anal. Chem. 70(4): 763-7, 1987.

(5) LYNDSAY, R. C. Other Desirable Constituentes of Food. In Principles of Food Science. Part I. Food Chemistry, Fennema, O. R. ed., Marcel Dekker, New York, 1976.

\section{6 - AGRADECIMENTOS}

Apoio financeiro foi fornecido pela Fundação de Amparo de Pesquisa do Estado de Minas Gerais - FAPEMIG. Dr. D. L. Nelson recebeu uma bolsa de pesquisa do Conselho Nacional de Desenvolvimento Científico e Tecnológico CNPq. 